\title{
Evidence-Based Changes in Devices and Methods of Endovascular Recanalization Therapy
}

\author{
Cheolkyu Jung, MD', Bae Ju Kwon, MD², Moon Hee Han, MD³
}

The devices and methods of endovascular recanalization therapy (ERT) have been rapidly developed and changed since PROACT II trial. Emerging as a treatment option in addition to intravenous or intraarterial thrombolysis, mechanical thrombectomy is currently being further developed and investigated as a potential first-line and stand-alone treatment. This review highlights and summarizes the recent clinical series and trials of the available devices and methods of ERT focusing on the multimodal approach.

Key Words : Brain; Cerebrovascular disorders; Stroke; Thrombolytic therapy;

Endovascular procedures

Reperfusion of the ischemic brain is the most effective therapy for acute ischemic stroke ever known and ever likely to be discovered [1]. By restoring nutritional blood flow to threatened tissues before they progress to infarction, reperfusion therapies salvage penumbral tissue, reduce final infarct size, and enable improved clinical outcomes [2].

In past 20 years, there were many developments in recanalization therapy of acute ischemic stroke. A new

\footnotetext{
'Department of Radiology, Seoul National University Bundang Hospital, Seongnam, Korea

${ }^{2}$ Department of Radiology, Kwandong University Myongji Hospital, Goyang, Korea

${ }^{3}$ Department of Radiology and Institute of Radiation Medicine, Seoul National University College of Medicine, Seoul, Korea

Received May 25, 2012;

accepted after revision July 12, 2012.

Correspondence to: Cheolkyu Jung, MD, Department of Radiology, Seoul National University Bundang Hospital, 300, Gumi-dong, Bundang-gu, Seongnam-si, Gyeonggi-do 463-787, Korea.

Tel. 82.31.787.7623 Fax. 82.31.787.4011

E-mail: cheolkyu.jung.ni@gmail.com

This is an Open Access article distributed under the terms of the Creative Commons Attribution Non-Commercial License (http://creativecommons.org/licenses/by-nc/3.0) which permits unrestricted non-commercial use, distribution, and reproduction in any medium, provided the original work is properly cited.
}

era in acute stroke care began in 1995, when the National Institute of Neurological Disorder and Stroke (NINDS) and recombinant tissue plasminogen activator (rtPA, alteplase) Stroke Study Group trial showed for the first time that intravenous thrombolysis (IVT) with rtPA can reverse neurologic deficit in acute stroke patients [3], although IVT has many limitations, such as strict inclusion criteria, short treatment time window, quite low recanalization rates, and substantial risk of symptomatic intracranial hemorrhage (SICH) [4]. A worldwide consensus recognizes the efficacy of reperfusion therapy for stroke, and an ongoing effort is being made to provide thrombolytic treatment to more patients, to extend the treatment window, to accelerate recanalization, and to increase complete recanalization rates with the help of other agents or devices or their combination.

Endovascular recanalization therapy (ERT) comprises a wide range of pharmacologic and mechanical techniques, such as intra-arterial thrombolysis (IAT), mechanical disruption and/or mechanical thrombectomy $[5,6]$. Although there is a growing amount of evidence that ERT may be effective treatment for patients with major vessel occlusion, it is unclear which device or technical strategy of ERTs is 
most effective for recanalization of occluded intracranial artery leading to better clinical outcome. This article summarizes the technical aspects of the ERT, reviews the technical and clinical results in the context of previous trials in acute ischemic stroke, and discusses the available treatment spectrum of ERT focusing on multimodal approach of ERT.

\section{Overview about the changes of devices and methods for ERT}

The Prolyse in Acute Cerebral Thromboembolism (PROACT) trials in the 1998 were the first to prove the safety and efficacy of IAT with pro-urokinase in patients with acute occlusion of the middle cerebral artery (MCA) within six hours from onset of symptom to treatment $[7,8]$. From then on, a variety of mechanical methods have been applied with or without the additional use of pharmacologic thrombolysis and been reported to further improve recanalization rates, including microwire manipulations, snare devices, balloon angioplasty, thrombus extraction, fragmentation, and/or aspiration [5].

The Mechanical Embolus Removal in Cerebral Ischemia (MERCI) retrieval system (Concentric Medical, Mountain View, CA, USA) was the first that U.S. Food and Drug Administration (FDA) approved as mechanical thrombectomy device in 2005 [9]. Basically, the core of the device is a corkscrew-shaped nitinol coil engaging the thrombus during thrombectomy [9]. To further improve recanalization, the device was also combined with IAT [10]. As a second device, the Penumbra system (Penumbra, Alameda, CA, USA) received FDA approval [11]. The device was specifically designed for vessel recanalization in acute stroke using a debulking and aspiration technique followed by direct thrombus extraction in the case of a remaining clot.

Balloon expandable stents were used as an adjunctive option in acute ischemic stroke, especially when the cause of occlusion was an in-situ stenoocclusive lesion [12]. The potential of self-expanding stents in the recanalization therapy of acute stroke was also added to the existing body of evidence as intracranial stent placement may have achieved an early and successful recanalization [13].

A critical stepping stone to improved clinical outcome after recanalization is the time to recanalization [14]. Stent deployment in occlusion site would allow for almost immediate flow restoration by thrombus entrapment between the stent struts and the vessel wall [15]. First FDA-approved prospective trial of primary intracranial self-expanding stents demonstrated technical feasibility, suggested efficacy for recanalization by self-expanding stents, and showed the good angiographic patency and clinical outcome at six months $[15,16]$. Although this trial showed the encouraging results, a major concern of permanent stenting was directed at the potential risk of in-stent thrombosis and thus the need for subsequent antithrombotic medication with an increased risk of intracranial hemorrhage [17].

Recently, stent retrievers, such as the Solitaire (ev3, Irvine, CA, USA), enabled thrombectomy by pulling back the deployed stent into the guide catheter while the struts of the stent engage the thrombotic material [18]. In contrast to conventional stent systems, stent retrievers do not require post-procedural antithrombotic therapy or anti-coagulant. The more recent development in clot retrieval is focused on these stentretrievers (Table 1) [19].

\section{Technical Outcomes of Various Methods}

\section{Intra-arterial thrombolysis}

According to the American Heart Association guidelines, IAT is an option for treatment within six hours for patients with an occlusion of the MCA, who are not candidates for IVT [20]. The PROACT II enrolled 180 patients and demonstrated that treated patients had better outcome ( $40 \%$ vs. $25 \%$ ) and much higher recanalization rate ( $66 \%$ vs. $18 \%)$ than the control group [8]. Although there was no statistically significant difference in mortality (25\%), symptomatic intracranial hemorrhage (SICH) in IAT group (10\%) occurred more frequently than the control group [8].

In 2002, Lisboa et al. [21] published a meta-analysis regarding the safety and efficacy of IAT. They performed a meta-analysis of 27 studies with a total of 852 patients who had received IAT and 100 control subjects, in the era before the mechanical thrombectomy trials. There were more favorable outcomes in the IAT group than in the control group $(41.5 \%$ versus $23 \%, P=0.002$ ), with a lower mortality rate for IAT (27.2\% versus $40 \%, P=0.004)$. The IAT group had an odds ratio (OR) of 2.4 (95\% Confidence Intervals (CI), $1.45-3.85)$ for favorable outcome, despite a higher frequency of $\operatorname{SICH}(9.5 \%$ versus $3 \%, P=0.046)$. They also remarked that IAT-treated supratentorial strokes were more likely to have favorable outcomes than infratentorial ones $(42.2 \%$ versus $25.6 \%, P=0.001$; OR, $2.0 ; 95 \%$ CI, $1.33-3.0)$. 


\section{Cheolkyu Jung, et al.}

Intra-arterial thrombolysis plus mechanical disruption

The Middle Cerebral Artery Embolism Local Fibrinolytic Intervention Trial (MELT) was one randomized trial, which was performed in Japan and was prematurely stopped after the approval of intravenous rtPA in that country [22]. Urokinase was used as thrombolytic agents instead of prourokinase or rtPA and mechanical disruption with a microwire was allowed. Patients within six hours of onset of symptom with angiographically proven middle cerebral artery (MCA) occlusion were randomized to receive urokinase or placebo. Like the results of PROACT II, a favorable outcome at 90 days, that was defined as modified Rankin score (mRS) 2 or less, was more frequent in the urokinase group than in the control group $(49.1 \%$ vs. $38.6 \%$; OR, 1.45 ; $95 \%$ CI, $0.73-$ $3.23)$, but there was no statistical significance $(P=0.345)$. This study suggested that IAT had the potential to increase the likelihood of excellent function outcome (mRS $0-1,42.1 \%$ vs. $22.8 \%$ in the urokinase and control groups, respectively; $P=0.045$; OR, 2.46; 95\% CI, 1.09-5.54).

Yoon et al. [23] reported the feasibility and efficacy of low-dose IAT using urokinase with aggressive mechanical clot disruption as rescue therapy for acute ischemic stroke after failure of intravenous thrombolysis. They prospectively enrolled twelve patients that consisted of two internal carotid artery terminus, eight M1 and two basilar artery occlusions. The recanalization was achieved in all cases and there was no SICH. The 3-months outcome was excellent ( $\mathrm{mRS}, 0-1)$ in eight patients, good (mRS, 2) in one patient, and poor $(\mathrm{mRS}, 3)$ in three patients.

Kim et al. [24] also assessed the feasibility of IAT with mechanical disruption using a microwire and microcatheter for acute ischemic stroke of MCA occlusion. They showed $94.7 \%$ of the recanalization rate (Thrombolysis in Myocardial infarction, TIMI 2), but there was no complete recanalization (TIMI 3 ) due to distal migration of thrombus into M3 or M4 branch. Distally migrated thrombus was resolved in $21.1 \%$.

\section{Permanent stenting as adjunctive therapy}

Stenting achieves recanalization by displacing the clot to the vessel wall or angioplasty for atherosclerotic stenosis $[12,25,26]$. Stenting as an adjunctive therapy has been used to restore flow after abrupt reocclusion occurring after recanalization with other modalities or to recanalize cases in which other modalities have failed to recanalize vessels [26].

\section{Permanent stenting as first-line therapy}

Intracranial stent placement for recanalization of cerebral arteries has been performed earlier in acute stroke patients [15, 25, 27]. Levy et al. [15] conducted the prospective single-arm Stent-assisted Recanalization in Acute Ischemic Stroke (SARIS) trial using the selfexpandable Wingspan stent (Stryker, Kalamazoo, MI, USA) in 20 patients with predominantly MCA occlusion (three basilar arteries) reporting again 100\% recanalization and $45 \%$ good outcome after one month.

\section{Temporary endovascular bypass}

This technique was first reported by Kelly et al. [28] who used the Enterprise stent for recanalization of an acute MCA occlusion. The Enterprise stent (Codman Neurovascular, Raynham, MA, USA) was delivered across the occlusion site and partially unconstrained for approximately 20 minutes, then recaptured and

Table 1. Different Stent-Retrievers*

\begin{tabular}{|c|c|c|c|c|}
\hline Stent-retrievers (manufacturer) & $\begin{array}{l}\text { Size, diameter and } \\
\text { length, } \mathrm{mm}\end{array}$ & Distal part & $\begin{array}{l}\text { Minimum } \\
\text { microcatheter ID, inch }\end{array}$ & Detachable \\
\hline \multirow[t]{2}{*}{ Solitaire FR (ev3) } & $4 \times 15,4 \times 20,4 \times 30$ & Open, 3 markers & 0.021 & Yes \\
\hline & $6 \times 20,6 \times 30$ & 4 markers & 0.027 & \\
\hline Trevo (Concetric Medical) & $4 \times 20$ & Closed, radiopaque tip & 0.021 & No \\
\hline Aperio (Acandis) & $4.5 \times 40$ & Open, 3 radiopaque markers & 0.027 & No \\
\hline Revive (Codman Endovascular) & $4.5 \times 22$ & Closed, radiopaque tip & 0.021 & No \\
\hline MindFrame Capture LP and & $3 \times 30,5 \times 30$ & Open, 2 markers & 0.0165 & No \\
\hline Flow LP (MindFrame) & & & & \\
\hline
\end{tabular}

*Source from reference 19

Abbreviations: ID, internal diameter 
removed. A second microcatheter during temporary endovascular bypass could be used to dissolve the residual thrombus trapped by the stent using the thrombolytics [29]. When this technique was used as rescue technique, Gonzalez et al. [30] achieved a 100\% recanalization rate to TIMI 2 and 3 with a $28 \%$ asymptomatic hemorrhagic transformation.

\section{Thrombectomy devices as first-line therapy}

Thrombectomy devices offer many potential advantages over pharmacologic thrombolysis, including more rapid achievement of recanalization, enhanced efficacy in treating large-vessel occlusions, and potentially lower risks for hemorrhagic events [31]. Currently, three thrombectomy devices have been cleared by the U.S. FDA through its $510(\mathrm{k})$ process: the MERCI retriever, the Penumbra system and the Solitaire stent.

\section{- MERCI}

MERCI trial was a prospective single-armed trial in which the device was deployed in all patients with occlusion of intracranial large arteries within eight hours of the onset of stroke symptoms and compared with the results in historical control group [9]. Of the 151 patients, recanalization was successful in $46 \%$. This is a much lower rate of recanalization than that was observed in the PROACT II trial. After adjunctive therapy (IA rtPA/urokinase, angioplasty, snare), the rate of recanalization increased to $60.3 \%$. In Multi MERCI trial, treatment with the retriever alone resulted in successful (TIMI 2-3) recanalization in $55 \%$ of treatable vessels and in $68 \%$ after adjunctive therapy (IA rtPA, mechanical).

\section{- Penumbra system}

The results of the pilot trial with the Penumbra System were excellent. It showed that recanalization before IAT was achieved in all treated cases $(48 \%$ TIMI 2; 52\% TIMI 3), and favorable outcome (a 4point or more National Institutes of Health Stroke Scale (NIHSS) improvement or mRS of 2 or less) at 30 days in $45 \%$ of the patients. The all-cause mortality rate was $45 \%$ [32]. Subsequently, the Penumbra Stroke Trial was conducted at 24 international centers in the United States and Europe. It was a prospective, single-arm multicenter trial and enrolled 125 patients. Complete or partial recanalization (TIMI 2-3) occurred in $81.6 \%$ of the occluded vessels [11].

Forced suction thrombectomy was the modified technique of Penumbra system [33]. Forced suction thrombectomy did not use the separator. It was performed by direct wedging between the tip of the reperfusion catheter and the proximal part of the clot followed forced suction by using a 20 - or $50-\mathrm{mL}$ syringe. A Thrombolysis in Cerebral Infarction (TICI) of $2 \mathrm{~b}$ or 3 was achieved in $81.9 \%$ of patients and a 3month favorable functional outcome (mRS, $0-2)$ in $45.5 \%$ of patients.

\section{- Stent-retrievers as first-line therapy}

Stent-retrievers offer the ability to provide immediate flow restoration after its placement, while being removable with clot trapped within the stent struts. So they do not require post-procedural anti-thrombotic therapy. Recent and ongoing studies are evaluating the use of stent-retrievers for managing acute ischemic stroke. Among these, the Solitaire stent was assessed in a series of 20 consecutive patients by Castano et al. [18], resulting in $90 \%$ recanalization and good outcome after three months in $45 \%$ of cases. No case required adjuvant therapy such as thrombolytics after deployment of the embolectomy device in $90 \%$ of cases. The reported number of passes for recanalization was 1.4, and the median time from groin puncture to recanalization was 50 minutes (range, 38-71 minutes). Comparable results have been reported by others for the Solitaire stent as exclusive device or in combination with IVT and IAT, or as rescue treatment after unsuccessful use of other mechanical devices in case series with up to 50 patients [34].

Recently, primary results of the Solitaire FR with the Intention for Thrombectomy (SWIFT) were presented at International Stroke Conference 2012 [35]. It was the multicenter, randomized, active comparator and non-inferiority trial and compared the Solitaire FR versus Merci as initial device for ERT. It was the first randomized clinical trial ever conducted on mechanical intervention for acute ischemic stroke. It was terminated early due to significantly better outcomes in the Solitaire stent group of the study. As a result of trial, FDA has cleared it as the product of thrombectomy for ERT. The study randomly assigned 113 stroke patients at 18 hospitals to a procedure to restore blood flow to the brain with either Solitaire FR or the Merci Retriever within eight hours of stroke onset. The Solitaire FR device showed a 2.5 times benefit in restoring blood flow to the brain, as determined by a blinded core lab, a 1.7 times improvement in poststroke neurological function and a 55\% reduction in mortality at 90 days. 


\section{Cheolkyu Jung, et al.}

\section{Bridging therapy}

A combined intravenous-endovascular approach, the "bridging" concept, has also been applied and investigated, and it seems to be used increasingly. In the prospective registry study REcanalisation using Combined intravenous Alteplase and Neurointerventional ALgorithm for acute Ischemic StrokE (RECANALISE), 167 patients with mainly anterior circulation stroke were either treated with IVT rt-PA alone or in a combined IVT- endovascular approach [36]. They showed that with high statistical significance, IVT- endovascular approach was superior over IVT alone with regard to recanalization ( $87 \%$ vs. $52 \%$ ) and, to a lesser degree, with regard to early neurologic improvement ( $60 \%$ vs. $39 \%)$. Outcome improvement at three months, however, did not reach significance. The IMS II [37] and the MultiMERCI [10] trials described above were also for the most part examples of the "bridging" concept in MCA stroke. For basilar artery (BA) occlusion, numerous case reports and two prospective case series have reported on a step-wise, combined IVT-IAT/MT approach as well. Roth et al. [38] have tested the Penumbra device after IVT in twelve patients with BA occlusion and saw 75\% recanalization and $66 \%$ short-term NIHSS improvement. Pfefferkorn et al. [39] employed a staged IVTendovascular approach to 16 patients with BA occlusion and reported even $94 \%$ recanalization and $44 \%$ good outcome at three months, which is remarkable in BA stroke.

\section{Clinical Outcomes of Endovascular Approach}

The focus of development has clearly moved from IAT to thrombectomy devices, especially stent-retrievers. This development is potentially promising, as (compared to earlier mechanical devices) stent-retrievers have the advantages of easy handling and relatively rapid restoration of antegrade flow after deployment of the device, independent of successful thrombectomy, thus saving time for the interventionalist and the brain. With regard to procedural safety, device-related complications, such as vasospasm or thrombus fragmentation, have been rarely reported [34].

The 2012 American College of Chest Physicians (ACCP) guidelines concluded that the available data regarding mechanical thrombectomy in acute ischemic stroke are of low quality up to date and leave considerable uncertainty regarding the impact of this intervention on survival and functional outcome [40]. A 2011 systematic review on mechanical thrombectomy identi- fied 87 studies published through November 2010 and showed that the included studies reported widely varying outcome rates of successful recanalization, good clinical outcome, SICH, complication, and mortality. The one clear finding was that successful recanalization predicted a good outcome [41].

\section{Futile Recanalization}

Recanalization correlates with good clinical outcome in most, but the impressive recanalization rates have not led to satisfying clinical benefits, as the percentage of patients with an $\mathrm{mRS} \leq 2$ (i.e., independence) at three months rarely exceed $45 \%$, the rate of SICH averages around $10 \%$, and mortality ranges between $26 \%$ and $36 \%$ [1]. Futile recanalization was defined as unfavorable outcome despite complete recanalization [42]. Although major studies on ERT did not specifically report the rate of futile recanalization, there was always a mismatch between recanalization and favorable outcome rates, suggesting that futile recanalization occurs in variable portions regardless of treatment strategy. In the PROACT II trial, the recanalization rate was $66 \%$, while the rate of favorable outcome was $40 \%$ ( $26 \%$ mismatch). The rate of futile recanalization in trials of thrombectomy devices was 54\% for MERCI trial, 51\% for Multi-MERCI and 71\% for Penumbra Pivotal trial $[9,10]$.

Higher rates of recanalization through the development of thrombectomy have not been matched by proportionally high rates of good functional outcome. Hussein et al. [42] suggested that futile recanalization was positively associated with age $>70$ years (OR, 4.4; 95\% CI, 1.9-10.5; $P=.0008)$, initial NIHSS score 1019 (OR, 3.8; 95\% CI, 1.7-8.4; $P=.001)$ and initial NIHSS score $\geq 20$ (OR, 64.4; 95\% CI, 28.8-144; $P<$ $.0001)$. This discrepancy between good technical and less satisfactory clinical results is certainly caused by multiple factors such as patient selection, time to treatment, duration of procedure, concomitant anticoagulation treatment, use and type of sedation, neuroanesthesiologic management, and post-procedural stroke care [43]. In order to reduce the futile recanalization, Rai et al. [44] made stress on pre-intervention perfusion imaging for treatment triage of ERT. They reported that despite similar or lower recanalization rates, there was a significantly higher rate of good outcomes in the recanalized population and thus a significantly lower rate of futile recanalization, compared with the previous trials (MERCI, MultiMERCI and Penumbra Pivotal trials).

Onset-to-recanalization time was also recognized as 


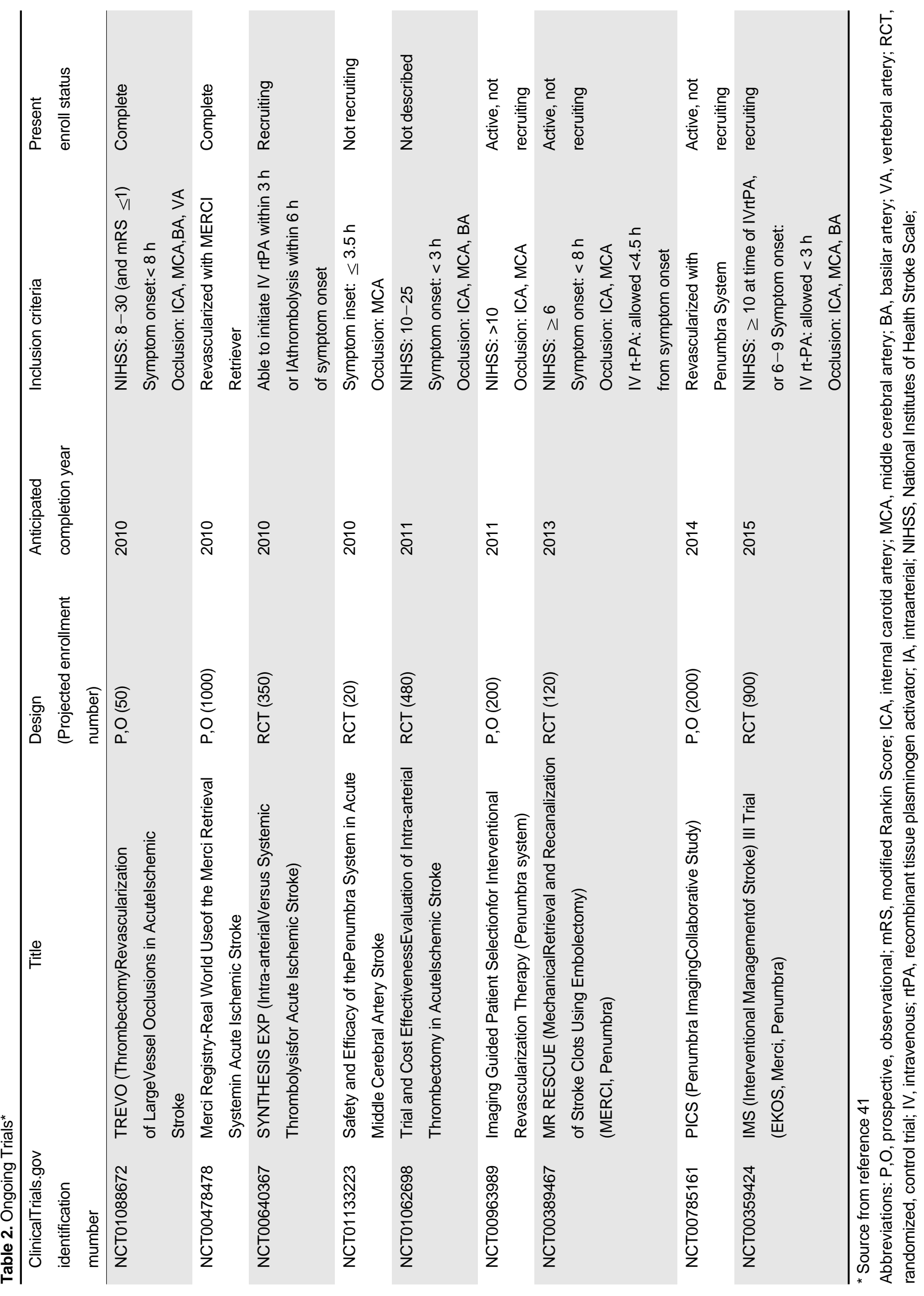




\section{Cheolkyu Jung, et al.}

an important modifier in treatment outcome. Goyal et al. [45] showed that the best outcomes are achieved among patients with higher Alberta Stroke Program Early CT Scale (ASPECTS) score and fast recanalization time. In their series, $62.5 \%$ of patients with onset to recanalization time $\leq 300$ minutes in the ASPECTS score $>7$ group had good clinical outcome when compared to $45.5 \%$ patients with either onset to recanalization time $>300$ minutes or no recanalization. In the ASPECTS score $\leq 7$ group, the corresponding figures are $33.3 \%$ with onset to recanalization time $\leq$ 300 minutes vs. $7.9 \%$ in the $>300$-minute group or no recanalization group.

\section{Hemorrhagic transformation}

Hemorrhagic transformation (HT) is a major complication of ERT. SICH following ERT for acute ischemic stroke is associated with a high rate of morbidity and mortality [46]. In NINDS trial, SICH occurred in $6.4 \%$ of patients given rtPA but only $0.6 \%$ of patients given placebo $(P<0.001)$ [3]. In PROACT II trial, SICH occurred in $10 \%$ of the pro-urokinase-treated patients and $2 \%$ of the placebo-treated patients $(P=.06)$ [8]. In MELT trial, SICH occurred in 9\% in urokinase-treated patients and $2 \%$ of the control patients $(P=0.206)$ [22]. In MERCI trial, SICH was observed in 11 of 141 (7.8\%) patients [9]. In Multi-MERCI trial, $\mathrm{SICH}$ occurred in 16 patients $(9.8 \%)$, four $(2.4 \%)$ of these were parenchymal hematoma type II, and clinically significant procedural complications occurred in nine (5.5\%) patients [10]. In Penumbra Pivotal trial, HT was observed in the 35 of 125 (28\%) on 24-hour CT, of which $14(11.2 \%)$ were symptomatic [11]. In a pilot study of Solitaire, SICH was found in two of $20(10 \%)$ patients [18].

Predictors of HT in patients receiving IAT might include higher NIHSS score, longer time to recanalization, lower platelet count, and higher glucose level with positive predictive value $70 \%$ and overall accuracy $78 \%$ [47]. Thrombolytics might have the toxic effect on blood brain barrier disruption in ischemic stroke [48]. Although introduction of thrombectomy devices, such as MERCI retriever, Penumbra system, or Solitaire stent, could reduce procedural recanalization time, defined as puncture time to recanalization as well as total dose of thrombolytics, rates of HT were similar among cases series and clinical trials on endovascular thrombolytics and mechanical thrombectomy.

In conclusion, the devices and techniques of ERT have been rapidly developed since PROACT II trial. Thanks to rapid development of mechanical thrombec- tomy, fast and complete recanalization of occluded large arteries could be achieved without thrombolytics or with low dose of thrombolytics. Despite higher recanalization rates and lessened procedure time, it has not been established whether or not mechanical thrombectomy for ERT improve clinical outcomes, so that further randomized controlled trials are needed to confirm the clinical efficacy (Table 2). In addition, image-based criteria for patient selection also must be established in order to reduce the futile recanalization and HT.

\section{References}

1. Rha JH, Saver JL. The impact of recanalization on ischemic stroke outcome: a meta-analysis. Stroke 2007;38:967-973

2. Molina CA, Saver JL. Extending reperfusion therapy for acute ischemic stroke: emerging pharmacological, mechanical, and imaging strategies. Stroke 2005;36:2311-2320

3. NINDS. Tissue plasminogen activator for acute ischemic stroke. The national institute of neurological disorders and stroke rt-PA stroke study group. N Engl J Med 1995;333:1581-1587

4. Goldemund D, Mikulik R. Reperfusion therapies for acute ischemic stroke. Curr Treat Options Neurol 2010;12:155-166

5. Nogueira RG, Schwamm LH, Hirsch JA. Endovascular approaches to acute stroke, part 1: Drugs, devices, and data. AJNR Am J Neuroradiol 2009;30:649-661

6. Rouchaud A, Mazighi M, Labreuche J, Meseguer E, Serfaty JM, Laissy JP, et al. Outcomes of mechanical endovascular therapy for acute ischemic stroke: a clinical registry study and systematic review. Stroke 2011;42:1289-1294

7. del Zoppo GJ, Higashida RT, Furlan AJ, Pessin MS, Rowley HA, Gent M. PROACT: a phase II randomized trial of recombinant pro-urokinase by direct arterial delivery in acute middle cerebral artery stroke. PROACT Investigators. Prolyse in Acute Cerebral Thromboembolism. Stroke 1998;29:4-11

8. Furlan A, Higashida R, Wechsler L, Gent M, Rowley H, Kase C, et al. Intra-arterial prourokinase for acute ischemic stroke. The PROACT II study: a randomized controlled trial. Prolyse in Acute Cerebral Thromboembolism. JAMA 1999;282:2003-2011

9. Smith WS, Sung G, Starkman S, Saver JL, Kidwell CS, Gobin YP, et al. Safety and efficacy of mechanical embolectomy in acute ischemic stroke: results of the MERCI trial. Stroke 2005;36:14321438

10. Smith WS, Sung G, Saver J, Budzik R, Duckwiler G, Liebeskind DS, et al. Mechanical thrombectomy for acute ischemic stroke: final results of the Multi MERCI trial. Stroke 2008;39:1205-1212

11. Penumbra Pivotal Stroke Trial Investigators. The penumbra pivotal stroke trial: safety and effectiveness of a new generation of mechanical devices for clot removal in intracranial large vessel occlusive disease. Stroke 2009;40:2761-2768

12. Lin DD, Gailloud P, Beauchamp NJ, Aldrich EM, Wityk RJ, Murphy KJ. Combined stent placement and thrombolysis in acute vertebrobasilar ischemic stroke. AJNR Am J Neuroradiol 2003;24: $1827-1833$

13. Sauvageau E, Levy EI. Self-expanding stent-assisted middle cerebral artery recanalization: technical note. Neuroradiology 


\section{Devices of Endovascular Recanalization Therapy}

2006;48:405-408

14. Humpich M, Singer OC, du Mesnil de Rochemont R, Foerch C, Lanfermann H, Neumann-Haefelin T. Effect of early and delayed recanalization on infarct pattern in proximal middle cerebral artery occlusion. Cerebrovasc Dis 2006;22:51-56

15. Levy EI, Siddiqui AH, Crumlish A, Snyder KV, Hauck EF, Fiorella DJ, et al. First Food and Drug Administration-approved prospective trial of primary intracranial stenting for acute stroke: SARIS (stent-assisted recanalization in acute ischemic stroke). Stroke 2009;40:3552-3556

16. Levy EI, Siddiqui AH, Crumlish A, Snyder KV, Hauck EF, Fiorella DJ, et al. Midterm clinical and angiographic follow-up for the first Food and Drug Administration-approved prospective, Single-Arm Trial of Primary Stenting for Stroke: SARIS (StentAssisted Recanalization for Acute Ischemic Stroke). Neurosurgery 2011;69:915-920

17. Gupta R, Tayal AH, Levy EI, Cheng-Ching E, Rai A, Liebeskind DS, et al. Intra-arterial thrombolysis or stent placement during endovascular treatment for acute ischemic stroke leads to the highest recanalization rate: results of a multicenter retrospective study. Neurosurgery 2011;68:1618-1623

18. Castaño C, Dorado L, Guerrero C, Millán M, Gomis M, Perez de la Ossa N, et al. Mechanical thrombectomy with the Solitaire AB device in large artery occlusions of the anterior circulation: a pilot study. Stroke 2010;41:1836-1840

19. Bosel J, Hacke W, Bendszus M, Rohde S. Treatment of Acute Ischemic Stroke With Clot Retrieval Devices. Curr Treat Options Cardiovasc Med 2012;14:260-272.

20. Adams HP Jr, del Zoppo G, Alberts MJ, Bhatt DL, Brass L, Furlan A, et al. Guidelines for the early management of adults with ischemic stroke: a guideline from the American Heart Association/American Stroke Association Stroke Council, Clinical Cardiology Council, Cardiovascular Radiology and Intervention Council, and the Atherosclerotic Peripheral Vascular Disease and Quality of Care Outcomes in Research Interdisciplinary Working Groups: The American Academy of Neurology affirms the value of this guideline as an educational tool for neurologists. Circulation 2007;115:e478-534

21. Lisboa RC, Jovanovic BD, Alberts MJ. Analysis of the safety and efficacy of intra-arterial thrombolytic therapy in ischemic stroke. Stroke 2002;33:2866-2871

22. Ogawa A, Mori E, Minematsu K, Taki W, Takahashi A, Nemoto $\mathrm{S}$, et al. Randomized trial of intraarterial infusion of urokinase within 6 hours of middle cerebral artery stroke: the middle cerebral artery embolism local fibrinolytic intervention trial (MELT) Japan. Stroke 2007;38:2633-2639

23. Yoon W, Park MS, Cho KH. Low-dose intra-arterial urokinase and aggressive mechanical clot disruption for acute ischemic stroke after failure of intravenous thrombolysis. AJNR Am J Neuroradiol 2010;31:161-164

24. Kim DJ, Kim DI, Byun JS, Jung JY, Suh SH, Kim EY, et al. Simple microwire and microcatheter mechanical thrombolysis with adjuvant intraarterial urokinase for treatment of hyperacute ischemic stroke patients. Acta Radiol 2008;49:351-357

25. Sauvageau E, Samuelson RM, Levy EI, Jeziorski AM, Mehta RA, Hopkins LN. Middle cerebral artery stenting for acute ischemic stroke after unsuccessful Merci retrieval. Neurosurgery 2007;60: 701-706

26. Gupta R, Vora NA, Horowitz MB, Tayal AH, Hammer MD,
Uchino K, et al. Multimodal reperfusion therapy for acute ischemic stroke: factors predicting vessel recanalization. Stroke 2006;37:986-990

27. Roth C, Papanagiotou P, Behnke S, Walter S, Haass A, Becker C, et al. Stent-assisted mechanical recanalization for treatment of acute intracerebral artery occlusions. Stroke 2010;41:2559-2567

28. Kelly ME, Furlan AJ, Fiorella D. Recanalization of an acute middle cerebral artery occlusion using a self-expanding, reconstrainable, intracranial microstent as a temporary endovascular bypass. Stroke 2008;39:1770-1773

29. Suh SH, Lee KY, Hong CK, Kim BM, Kim CH, Chung TS, et al. Temporary stenting and retrieval of the self-expandable, intracranial stent in acute middle cerebral artery occlusion. Neuroradiology 2009;51:541-544

30. Gonzalez LF, Jabbour P, Tjoumakaris S, Teufack S, Gordon D, Dumont A, et al. Temporary endovascular bypass: rescue technique during mechanical thrombolysis. Neurosurgery 2012;70:245-252

31. Thomassen L, Bakke SJ. Endovascular reperfusion therapy in acute ischaemic stroke. Acta Neurol Scand Suppl 2007;187:22-29

32. Bose A, Henkes H, Alfke K, Reith W, Mayer TE, Berlis A, et al. The Penumbra System: a mechanical device for the treatment of acute stroke due to thromboembolism. AJNR Am J Neuroradiol 2008;29:1409-1413

33. Kang DH, Hwang YH, Kim YS, Park J, Kwon O, Jung C. Direct thrombus retrieval using the reperfusion catheter of the penumbra system: forced-suction thrombectomy in acute ischemic stroke. AJNR Am J Neuroradiol 2011;32:283-287

34. Costalat V, Machi P, Lobotesis K, Maldonado I, Vendrell JF, Riquelme C, et al. Rescue, combined, and stand-alone thrombectomy in the management of large vessel occlusion stroke using the solitaire device: a prospective 50-patient single-center study: timing, safety, and efficacy. Stroke 2011;42:1929-1935

35. Saver JL, Jahan R, Levy EI, Jovin TG, Baxter B, Nogueira R, et al. Primary Resultus of the SOLITAIRE FR With the Intention for Thrombectomy (SWIFT) Multicenter, Randomized Clinical Trial. Jan. 31-Feb. 3, in New Orleans, International Stroke Conference 2012

36. Mazighi M, Serfaty JM, Labreuche J, Laissy JP, Meseguer E, Lavallée PC, et al. Comparison of intravenous alteplase with a combined intravenous-endovascular approach in patients with stroke and confirmed arterial occlusion (RECANALISE study): a prospective cohort study. Lancet Neurol 2009;8:802-809

37. IMS II Trial Investigators. The Interventional Management of Stroke (IMS) II Study. Stroke 2007;38:2127-2135

38. Roth C, Mielke A, Siekmann R, Ferbert A. First experiences with a new device for mechanical thrombectomy in acute basilar artery occlusion. Cerebrovasc Dis 2011;32:28-34

39. Pfefferkorn T, Mayer TE, Opherk C, Peters N, Straube A, Pfister $\mathrm{HW}$, et al. Staged escalation therapy in acute basilar artery occlusion: intravenous thrombolysis and on-demand consecutive endovascular mechanical thrombectomy: preliminary experience in 16 patients. Stroke 2008;39:1496-1500

40. Lansberg MG, O’Donnell MJ, Khatri P, Lang ES, Nguyen-Huynh MN, Schwartz NE, et al. Antithrombotic and thrombolytic therapy for ischemic stroke: Antithrombotic Therapy and Prevention of Thrombosis, 9th ed: American College of Chest Physicians Evidence-Based Clinical Practice Guidelines. Chest 2012;141: e601S-636S 


\section{Cheolkyu Jung, et al.}

41. Baker WL, Colby JA, Tongbram V, Talati R, Silverman IE, White $\mathrm{CM}$, et al. Neurothrombectomy devices for the treatment of acute ischemic stroke: state of the evidence. Ann Intern Med 2011;154: 243-252

42. Hussein HM, Georgiadis AL, Vazquez G, Miley JT, Memon MZ, Mohammad YM, et al. Occurrence and predictors of futile recanalization following endovascular treatment among patients with acute ischemic stroke: a multicenter study. AJNR Am J Neuroradiol 2010;31:454-458

43. Molina CA. Futile recanalization in mechanical embolectomy trials: a call to improve selection of patients for revascularization. Stroke 2010;41:842-843

44. Rai AT, Raghuram K, Domico J, Hobbs G, Carpenter J. Preintervention triage incorporating perfusion imaging improves outcomes in patients undergoing endovascular stroke therapy: a comparison with the device trials. J Neurointerv Surg 2012
45. Goyal M, Menon BK, Coutts SB, Hill MD, Demchuk AM. Effect of baseline CT scan appearance and time to recanalization on clinical outcomes in endovascular thrombectomy of acute ischemic strokes. Stroke 2011;42:93-97

46. Lansberg MG, Albers GW, Wijman CA. Symptomatic intracerebral hemorrhage following thrombolytic therapy for acute ischemic stroke: a review of the risk factors. Cerebrovasc Dis 2007;24:1-10

47. Kidwell CS, Saver JL, Carneado J, Sayre J, Starkman S, Duckwiler G, et al. Predictors of hemorrhagic transformation in patients receiving intra-arterial thrombolysis. Stroke 2002;33:717724

48. Kidwell CS, Latour L, Saver JL, Alger JR, Starkman S, Duckwiler $\mathrm{G}$, et al. Thrombolytic toxicity: blood brain barrier disruption in human ischemic stroke. Cerebrovasc Dis 2008;25:338-343 